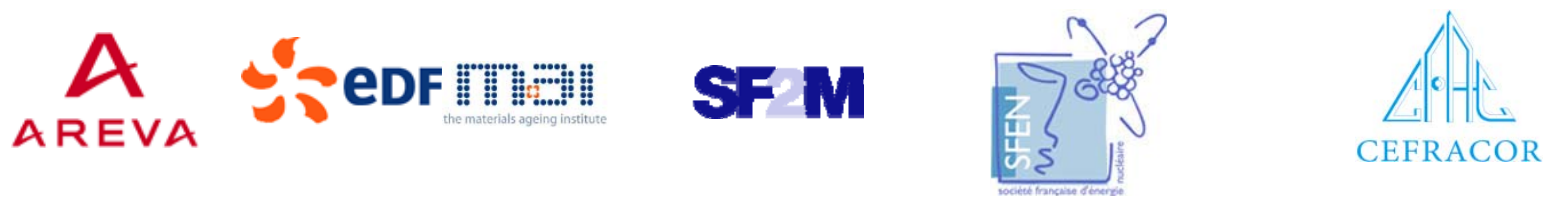

\section{MIN口S}

Centre of Excellence for Nuclear Materials

\section{Workshop}

Materials Innovation for Nuclear Optimized Systems
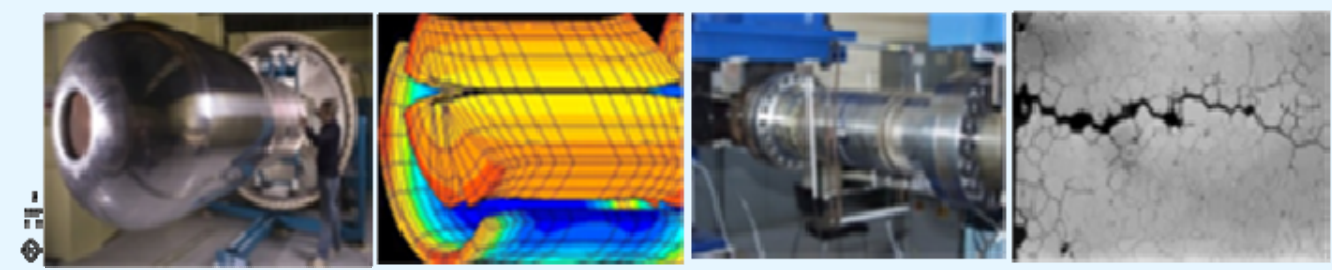

December 5-7, 2012, CEA - INSTN Saclay, France

\section{Christelle DUGUAY}

CEA (France)

Mastery of $(\mathrm{U}, \mathrm{Pu}) \mathrm{C}$ Carbide fuel: from Raw Materials to Final Characteristics

Workshop organized by:

Christophe GALLÉ, CEA/MINOS, Saclay - christophe.galle@cea.fr Constantin MEIS, CEA/INSTN, Saclay - constantin.meis@cea.fr 


\title{
Mastery of (U,Pu)C Carbide Fuel: from Raw Materials to Final Characteristics
}

\author{
Christelle DUGUAY ${ }^{1}$ \\ ${ }^{1}$ CEA-DEN-DEC, Service Plutonium Uranium et Actinides Mineurs, SPUA (Cadarache, France)
}

Mixed uranium plutonium carbide is for many years an advanced and alternative fuel to the mixed oxide being developed for Gas and Sodium Fast Reactors due to its high thermal conductivity and heavy-metal density [1].

Compared to that of oxide fuels, the fabrication of carbide fuels meeting all required specifications (among which are an oxygen content lower than $1000 \mathrm{ppm}$ and a predominant open porosity $\left.\mathrm{P}_{\mathrm{o}} / \mathrm{P}_{\mathrm{t}}>50 \%\right)$ is a much more difficult and challenging task. Due to their extreme reactivity with oxygen and moisture, fabrication and handling of carbide fuels are indeed performed in gloveboxes maintained at purity levels needed to provide operational safety and to obtain high-quality fuels, under a dynamic flow of nitrogen $\left(\mathrm{O}_{2}\right.$ and $\mathrm{H}_{2} \mathrm{O}$, each less than $\left.50 \mathrm{ppm}\right)$. Nevertheless, oxygen pick up during processing of the material seems unavoidable, even at room temperature, and must be thus limited by suitable procedures.

A significant loss of plutonium may also be caused by vaporization during the heating steps, especially at high temperatures. Such a loss must be limited for radiological reasons (the evaporated plutonium condenses in the cold parts of furnaces) and since it affects the composition of the carbide.

As shown on the simplified flow sheet presented in fig.1, the main steps in the fabrication of carbide fuel pellets are as follows:

- Vacuum carbothermic synthesis of carbide fuel in the temperature range of $1450-1650^{\circ} \mathrm{C}$ from a blend of $\mathrm{UO}_{2}, \mathrm{PuO}_{2}$ and graphite powders pressed into compacts,

- Crushing and milling of compacted samples,

- Consolidation of carbide powders into fuel pellets by cold pressing and sintering at $1750^{\circ} \mathrm{C}$ under $\mathrm{Ar}+5 \% \mathrm{H}_{2}$ gas,

To achieve specified pellet density ( $80 \%$ TD) and porosity, a pore former (such as zinc stearate) can be added to the fuel powder.

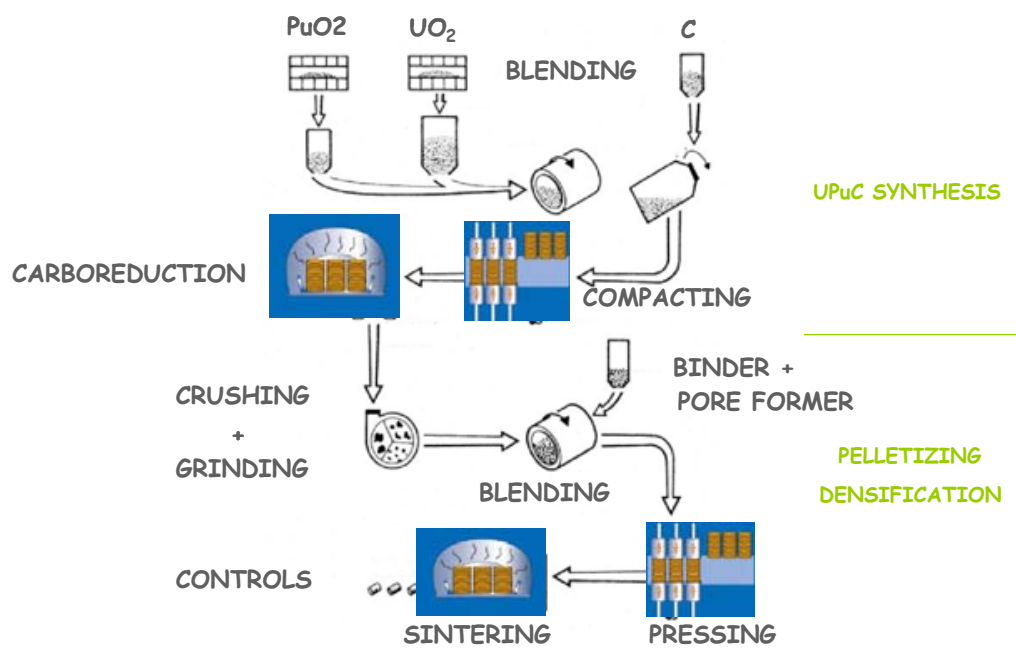

This is an Open Access article distributed under the terms of the Creative Commons Attribution License 2.0, which permits unrestricted use, distribution, and reproduction in any medium, provided the original work is properly cited. 
Fig. 1: Mixed carbide pellets fabrication flowsheet.

The sintered carbides are mainly composed of a monocarbide phase $(\mathrm{U}, \mathrm{Pu}) \mathrm{C}$, with traces of a sesquicarbure phase $(\mathrm{U}, \mathrm{Pu})_{2} \mathrm{C}_{3}$. Their density reaches $75 \%$ (when pore former is added) to $91 \%$ of theoretical density. They contain residual oxygen as impurity in varying amounts, depending on the fabrication conditions, and above the upper specified limit. The residual oxygen content decreases when the open porosity increases (fig. 2). For an open porosity higher than $40 \%$, relatively low levels of oxygen, between 1000 and 3000 ppm, can be obtained, even if the raw carbide powder has a high oxygen content (sintering classically leads to a significant reduction in the oxygen content).

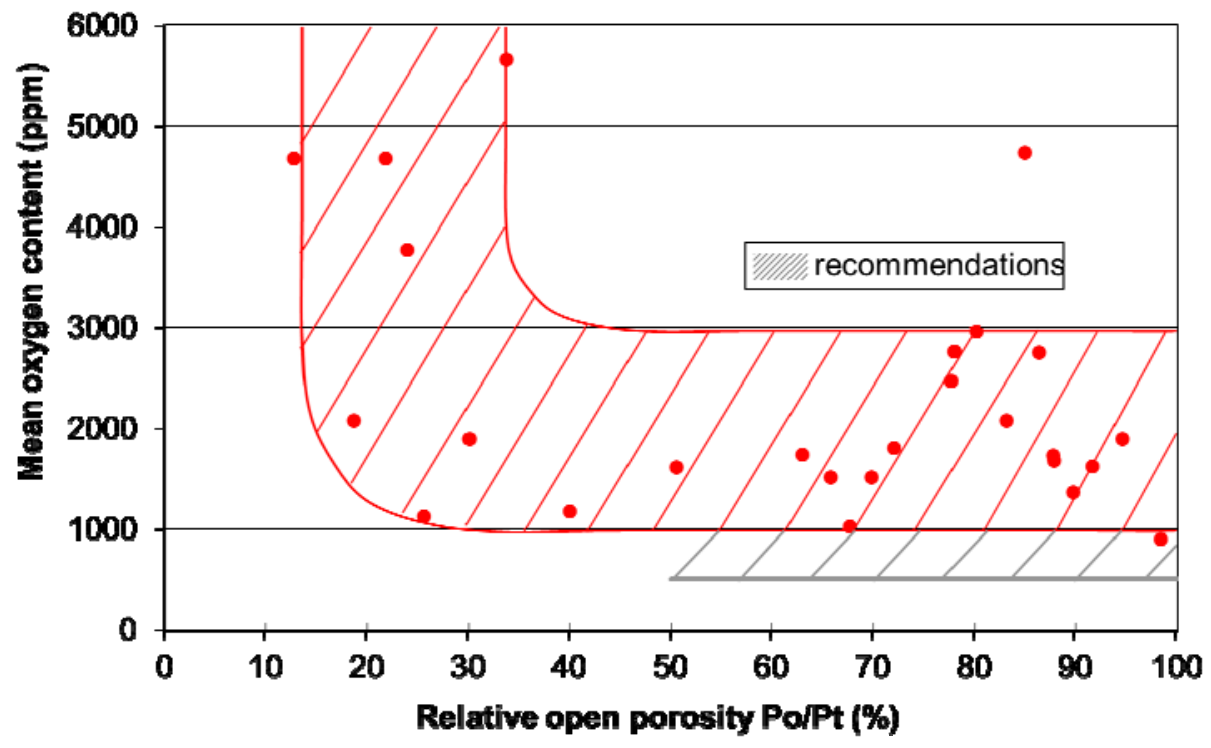

Fig. 2: Carbides oxygen content as a function of their open porosity.

The use of new oxide precursors, whose synthesis is based on the co-conversion of actinides [2], may simplify the manufacturing process by reducing the number of process steps, and may avoid the additional oxygen contamination of the final product as well as the radiation exposure of the operators. Faster reaction rates during carbothermic reduction could be achieved, as well as complete conversion of oxides to carbide at relatively low temperatures so as to keep plutonium volatilization at a reasonably low level.

So, $(\mathrm{U}, \mathrm{Pu}) \mathrm{O}_{2}$ or even precursors obtained by direct incorporation of carbon graphite or a carbon molecule in the structure of the mixed oxalate could be used as starting materials instead of $\mathrm{UO}_{2}$ and $\mathrm{PuO}_{2}$.

\section{References}

[1] Hj. Matzke, Science of advanced LMFBR fuels. A Monograph on sold State Physics, Chemistry and Technology of Carbides, Nitrites and Carbonitrides of Uranium and Plutonium. Elsevier Science \& Technology Books, 1986.

[2] A. Handshuh, Synthèse des carbures d'U-Pu : influence des précurseurs et mécanismes réactionnels de la carbothermie des systèmes lanthanides et actinides. These de Doctorat de l'Université des Sciences et technologies de Lille, octobre 2010. 
DE LA RECHERCHE À L'INDUSTRIE

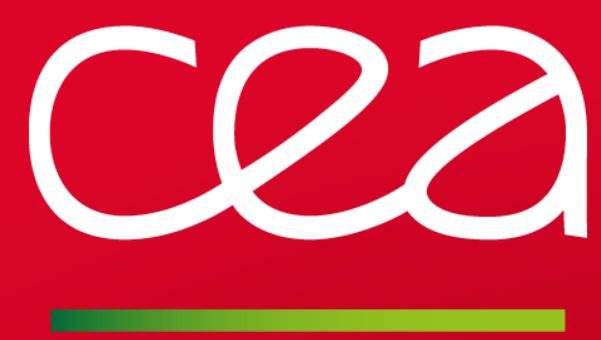

\title{
MASTERY OF (U,PU)C CARBIDE FUEL: FROM RAW MATERIALS
}

\section{TO FINAL CHARACTERISTICS}

\author{
CHRISTELLE DUGUAY \\ NUCLEAR ENERGY DIVISION, FUEL STUDIES DEPARTMENT, \\ CEA CADARACHE, FRANCE
}




\section{OUTLINE OF THE PRESENTATION}

MINDS 1 - Mixed carbide: an advanced fuel for fast reactors

In comparison to oxide fuels, carbide fuels...

The U-PU-C system

Carbide fuel specifications

Required fuels are...

2 - Mixed carbide fabrication and characterization

Reference fabrication process

First step of fabrication: carbide synthesis

Second step of fabrication: carbide sintering

Carbide characterization

Alternative fabrication routes

Co-converted oxides used as precursors

3 - Manufactured mixed carbides

Carbide composition

Achievement of different densities

Achievement of different open porosities

Carbide oxygen content

4 - Conclusions and prospects

Conclusions

Efforts must now focus on... 
1-An advanced fuel

2-Fabrication process and controls

3-Experimental results

4-Conclusions and prospects
MIXED CARBIDE: AN ADVANCED FUEL FOR FAST REACTORS 


\section{cea}

\section{IN COMPARISON TO OXIDE FUELS, CARBIDE FUELS...}

\section{MIN口S}

present:

$\checkmark$ a higher metal atom density $\left(12.9 \mathrm{~g} . \mathrm{cm}^{-3}\right.$ vs $\left.9.8 \mathrm{~g} . \mathrm{cm}^{-3}\right)$

$\checkmark$ a better thermal conductivity (18.8 W.m. $\mathrm{m}^{-1} \cdot \mathrm{K}^{-1} \mathrm{vs} 2.4 \mathrm{~W} \cdot \mathrm{m}^{-1} \cdot \mathrm{K}^{-1}$ at 1000K)

$\Leftrightarrow$ higher specific power operation and higher breeding ratio

$\rightarrow$ a great potential for Fast Reactors

$\rightarrow$ are less developed (less irradiation experience) and their fabrication poses an additional hazard due to their pyrophoric nature $\Rightarrow$ fabrication and handling in an inert atmosphere

$\Leftrightarrow$ a need for:

$\checkmark$ a demonstration study of feasibility of fabricating a reliable carbide fuel on a laboratory scale

$\checkmark$ an optimization of the fabrication parameters of fuel pellets 


\section{THE U-PU-C SYSTEM}

\section{MINDS}

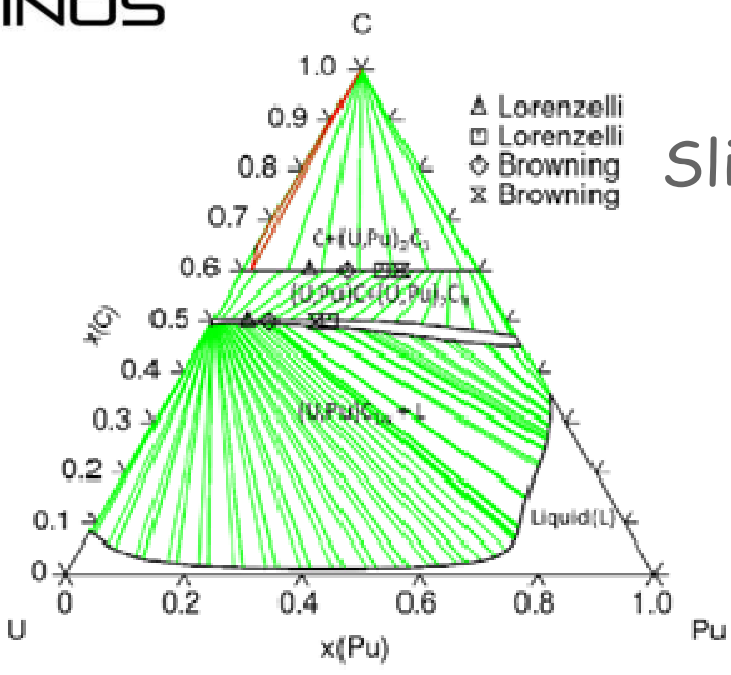

Slightly hyperstoichiometric fuels

$$
\mathrm{C} /(\mathrm{U}+\mathrm{Pu})>1
$$

$\Leftrightarrow$ Two phases in presence: $(U, P u) C$ and $(U, P u)_{2} C_{3}$

$$
\text { At } 1773 \mathrm{~K}
$$

Pu loss by vaporization: $\mathrm{Pu}(\mathrm{g})$ and $\mathrm{PuO}(\mathrm{g})$, enhanced at high temperatures

\section{S. Vaudez et al,}

Global 2007 Proceedings, Boise Idaho, USA, Sept. 9-13, 2007
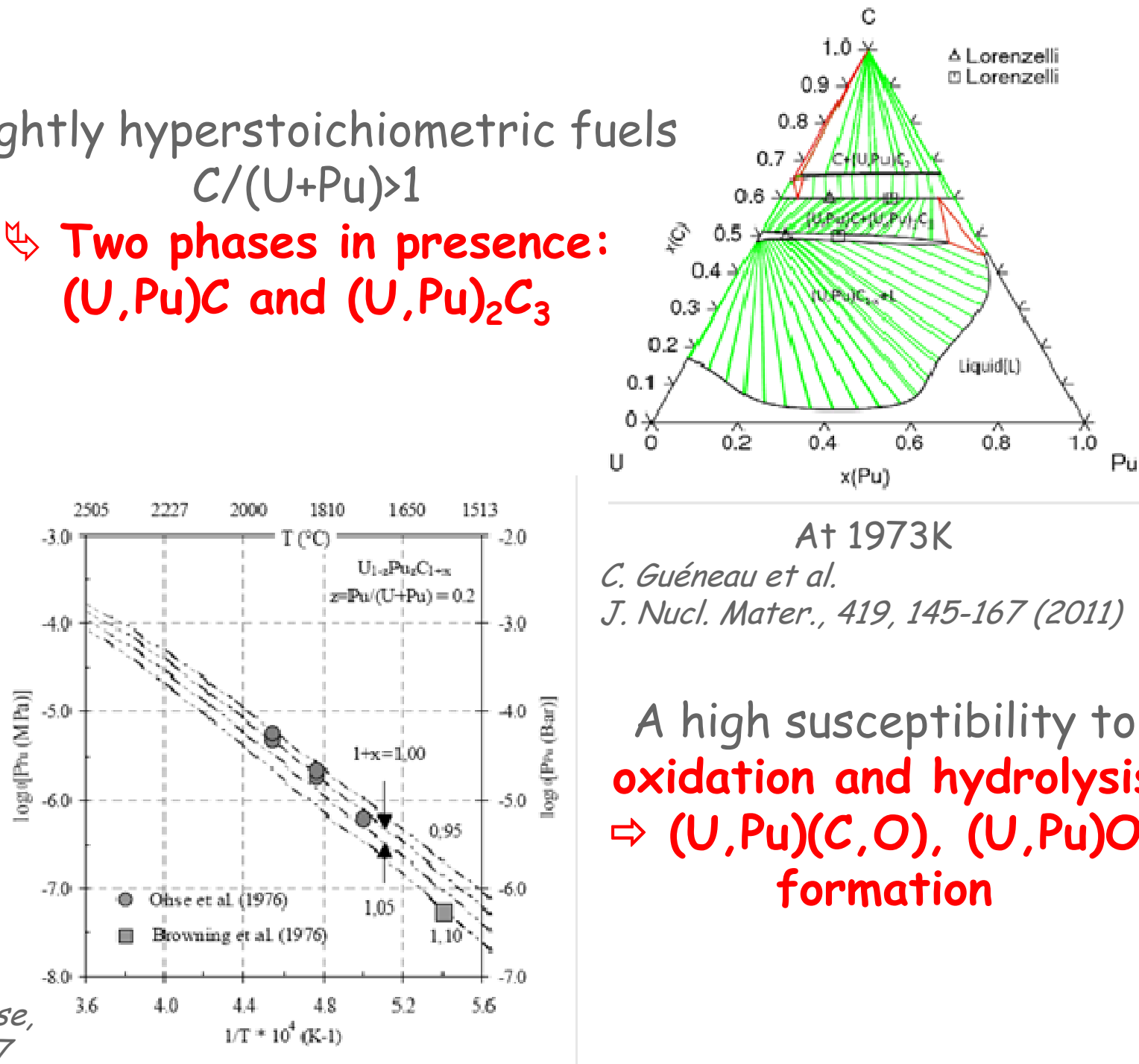

$$
\begin{aligned}
& \text { At 1973K } \\
& \text { C. Guéneau et al. } \\
& \text { J. Nucl. Mater., 419, 145-167 (2011) }
\end{aligned}
$$

A high susceptibility to oxidation and hydrolysis $\Rightarrow(U, P u)(C, O),(U, P u) O_{2}$ formation 


\section{CEA CARBIDE FUEL SPECIFICATIONS}

\section{MIN口S}

resulting from irradiation feedback:

$>$ A plutonium content of the order of $18 \%$, the mean value for GFR fuel.

$>$ A sintered density of 80 to $85 \%$ of theoretical, to partially accommodate the fuel swelling and limit the cladding mechanical interaction to yield decent burnup without breaking.

$>$ A predominant open porosity ( $\mathrm{Po} / \mathrm{Pt}>50 \%$ ) which promotes the release of fission gases.

$>$ An oxygen content between 500 and 1000 ppm, to limit the degradation of the irradiation behavior of the $(U, P u) C$ phase.

$>A$ sesquicarbide content $(U, P u)_{2} C_{3}$ between 5 and $10 \mathrm{Vol} . \%$ to avoid the presence of a metallic phase with a low melting point, while reducing the risk of clad failure by carburization.

$>$ A minimum metallic impurities content $(\mathrm{Na}, \mathrm{Si}, \mathrm{Cl}, \mathrm{F})$.

$\stackrel{\leftrightarrow}{\Rightarrow}$ A challenging task to meet all these specifications simultaneously! 


\section{REQUIRED FUELS ARE...}

\section{MINDS}

globally comparable to those produced and characterized for understanding studies and irradiation programs in the early 1960's (France) and in the 1980-1990's (Japan, Germany, USA).

but with a more stringent recommendation for the oxygen content than what used to be specified (tolerance up to $3000 \mathrm{ppm}$ ).

very different in their composition from Indian fuels manufactured from the 1980's:

$\checkmark 55 \%<[\mathrm{Pu}]<70 \%$ (mixed carbide used as the driver fuel for the Fast Breeder Test Reactor, Indira Gandhi Centre for Atomic Research, India, since 1985)

$\checkmark$ [O] up to 5000-6000 ppm

$\checkmark\left[M_{2} C_{3}\right]$ up to $20 \%$ 
1 - An advanced fuel

2-Fabrication process and controls

3-Experimental results

4-Conclusions and prospects
MIXED CARBIDE FABRICATION AND CHARACTERIZATION 


\section{CQA REFERENCE FABRICATION PROCESS}

\section{MINDS a two-step procedure}

in glove boxes under dynamic flow of nitrogen (3 renewals $/ \mathrm{h}$ ), with $\left[\mathrm{O}_{2}\right]$ and $\left[\mathrm{H}_{2} \mathrm{O}\right]<50 \mathrm{ppm}$ each Carbide storage in specific sealed containers
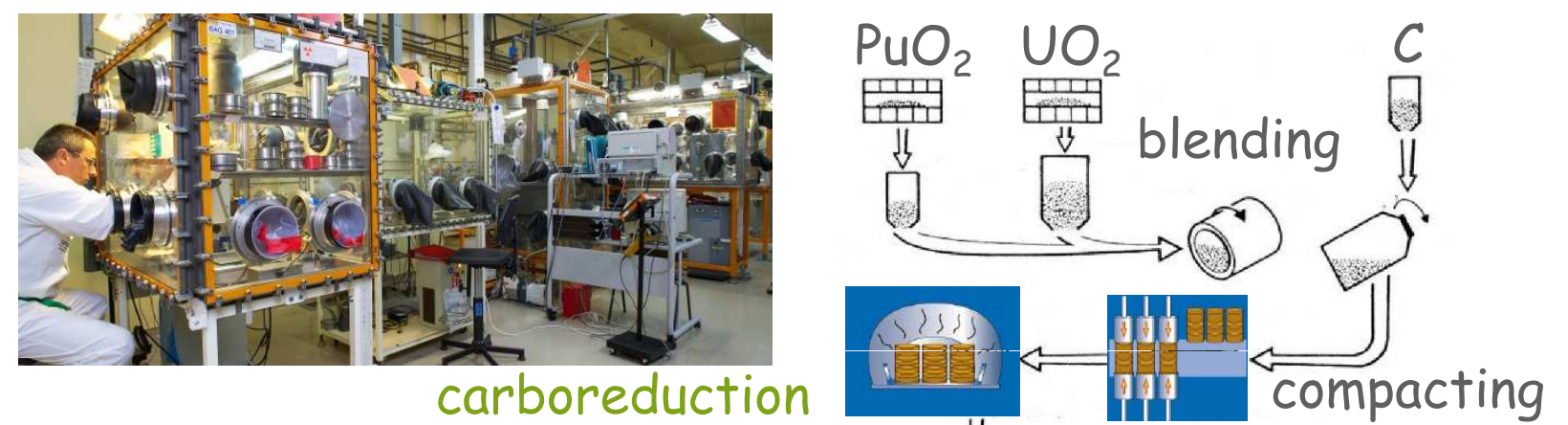

(U,Pu)C

carboreduction

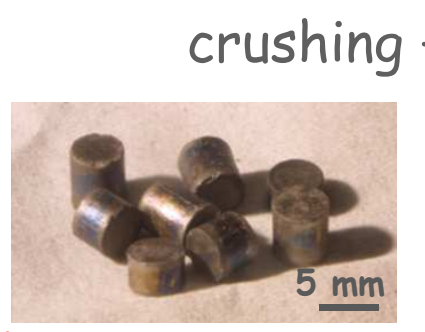

Some limitations:

controls

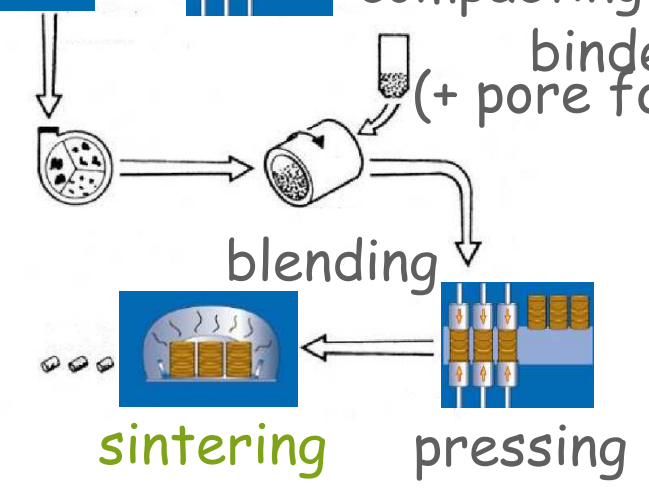

synthesis

$\checkmark$ many process steps

$\checkmark$ plutonium (and also americium) volatilization

$\checkmark$ carbide reactivity with oxygen... 


\section{CQA FIRST STEP OF FABRICATION: CARBIDE SYNTHESIS}

MINDS

$\mathrm{UO}_{2}-\mathrm{PuO}_{2}$ blend $\mathrm{Pu} /(\mathrm{U}+\mathrm{Pu}) \sim 15 \%$

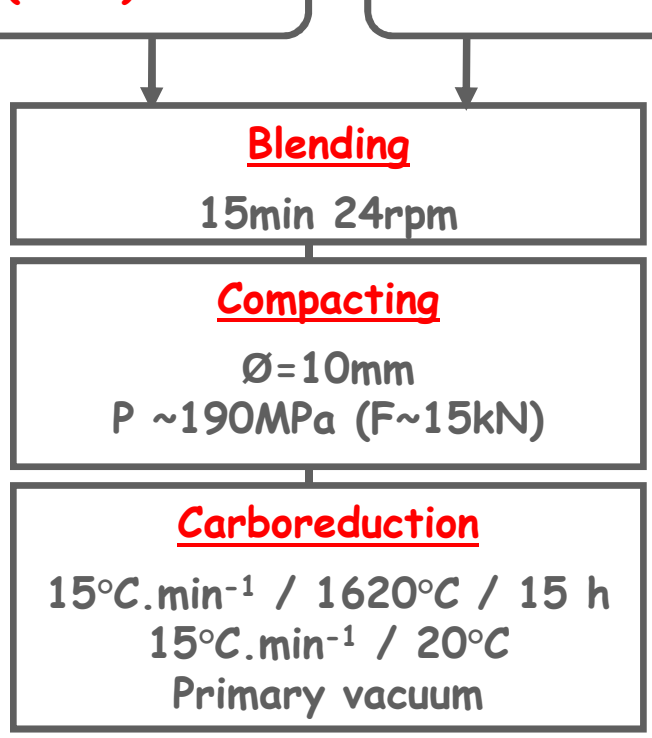

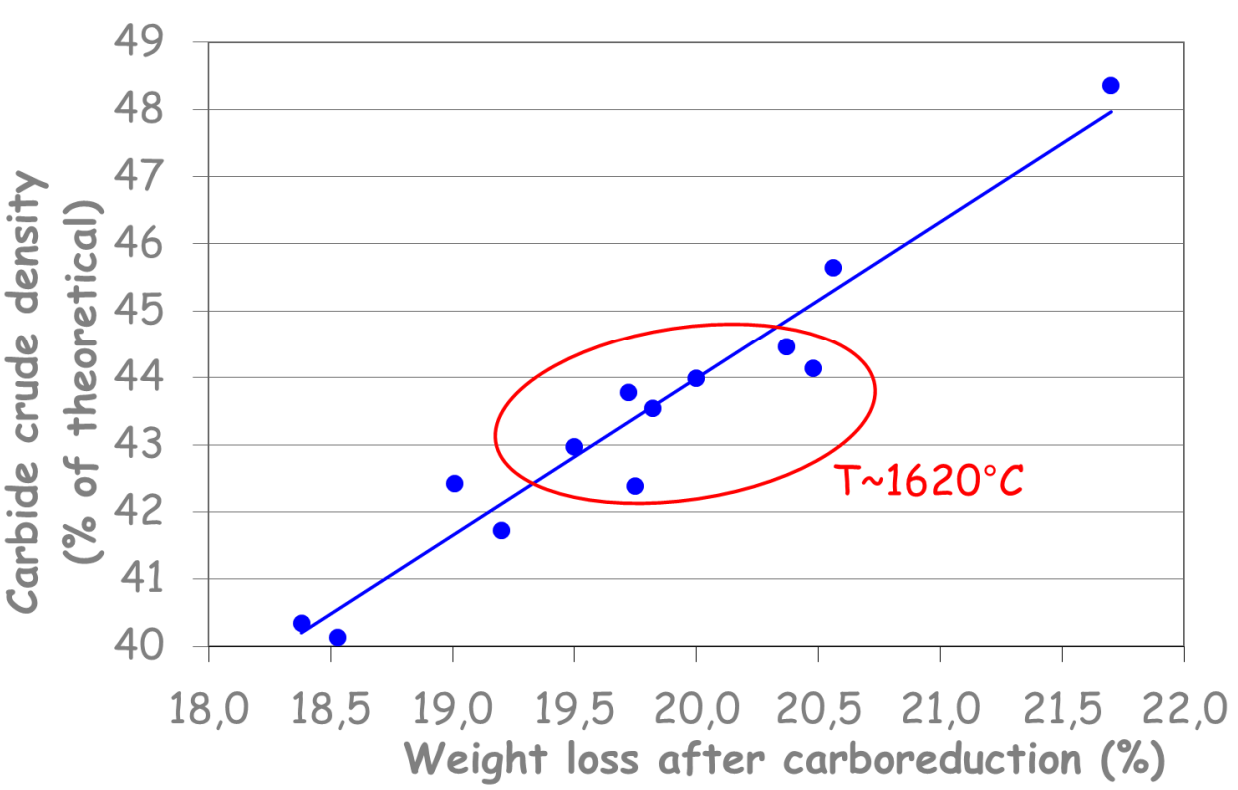

$(1-x) \mathrm{UO}_{2}+x \mathrm{PuO}_{2}+(3+y) C \rightarrow\left(U_{1-x}, \mathrm{Pu}_{x}\right) \mathrm{C}+\left(\mathrm{U}_{1-y}, \mathrm{Pu}_{\mathrm{y}}\right)_{2} \mathrm{C}_{3}+2 \mathrm{CO}$

Theoretical weight loss $\sim 18.5 \%$ (CO gas release, no plutonium vaporization) Experimental weight losses around $20 \%$ (slight amount of $\mathrm{CO}_{2}$ gas, plutonium vaporization)
ऽ oxygen content
$\gtrsim T: \gtrsim P u$ loss
$\diamond$ carbide crude density (and occluded $\mathrm{CO}$ )

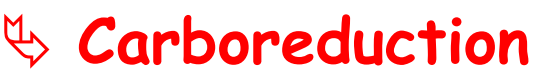 at $\sim 1620^{\circ} \mathrm{C}$ 


\section{CEZ SECOND STEP OF FABRICATION: CARBIDE SINTERING}

\section{MINDS}

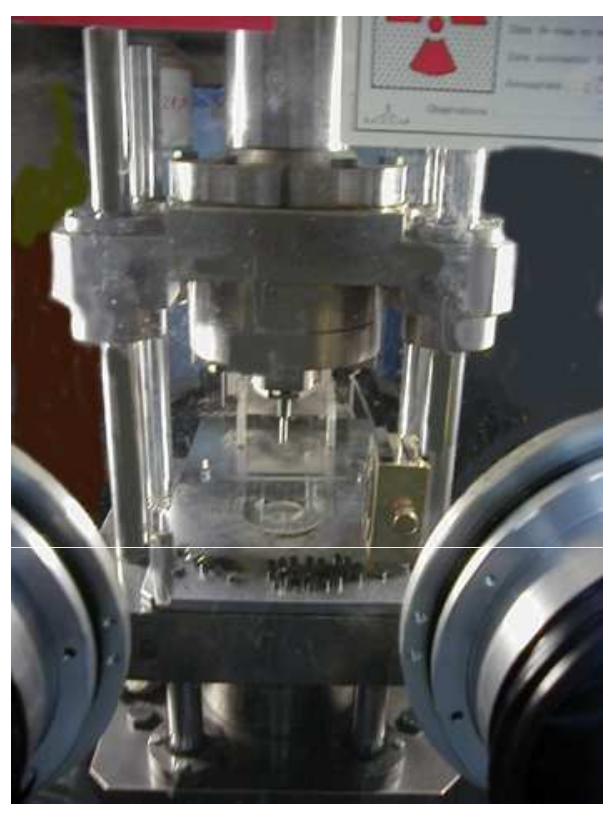

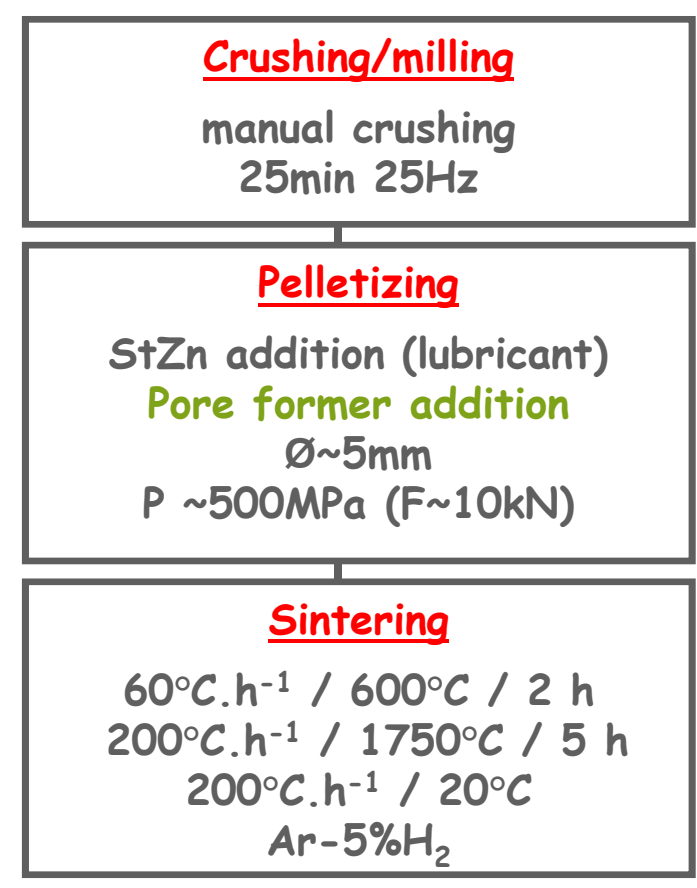

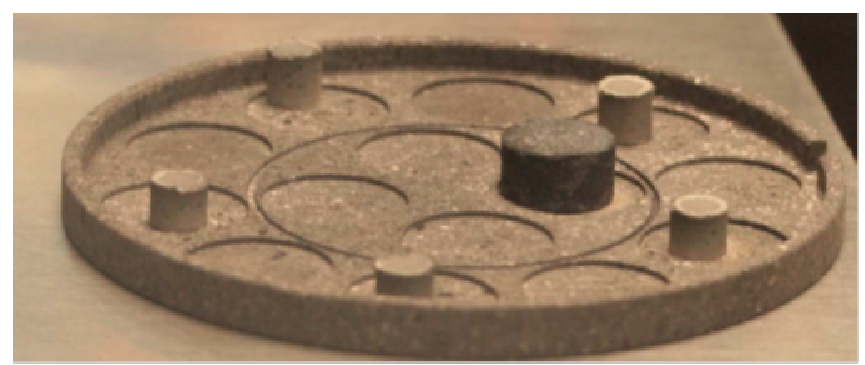

green pellet density $\sim 65 \%$ of theoretical (Dth $=13,61 \mathrm{~g} . \mathrm{cm}^{-3}$ ) sintered density $\sim 91 \%$ of theoretical, with a fraction of open porosity $\sim 3 \%$, (Po/Pf 33\%) without pore former

pore formers used: $\mathrm{StZn}\left(\mathrm{Zn}\left(\mathrm{C}_{18} \mathrm{H}_{35} \mathrm{O}_{2}\right)_{2}\right)$, StCa $\left(\mathrm{Ca}\left(\mathrm{C}_{18} \mathrm{H}_{35} \mathrm{O}_{2}\right)_{2}\right)$ and $A Z B$ $\left(\mathrm{C}_{2} \mathrm{H}_{4} \mathrm{O}_{2} \mathrm{~N}_{4}\right)$, up to 3 wt\% 


\section{CEA CARBIDE CHARACTERIZATION (1/2)}

\section{MIN口S}

* Determination of the sintered density

by Archimedes' method using bromobenzen as a medium

Composition analysis after synthesis (before and after milling) as well as after sintering on powder specimens

- Determination of the oxygen content

by the inert gas fusion principle using a LECO TC600 analyzer

Oxygen can be :

$\checkmark$ adsorbed at the surface,

$\checkmark$ present as "surface oxide layer",

$\checkmark$ present as $(U, \mathrm{Pu}) \mathrm{O}_{2}$ precipitate,

$\checkmark$ in solution of the type $(U, P u)(C, O)$.
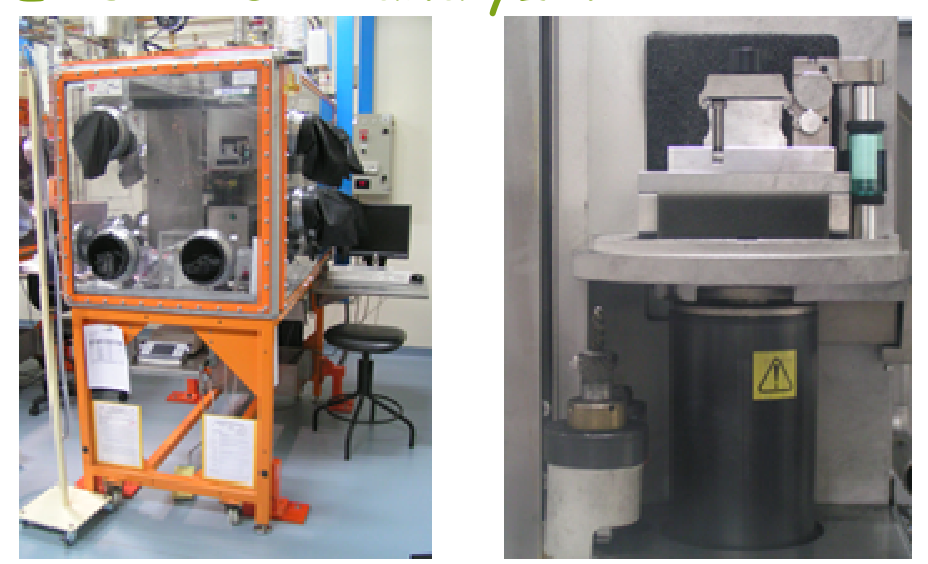

- Phase identification by X-Ray Diffraction

on a Siemens D5000 X-ray diffractometer

mixture of the fuel powder with epoxy resin mounted on a sample holder 


\section{CEA CARBIDE CHARACTERIZATION (2/2)}

\section{$\because \mathrm{MINDS}$}

* Ceramographic examination

after mechanical polishing of resin mounted specimens

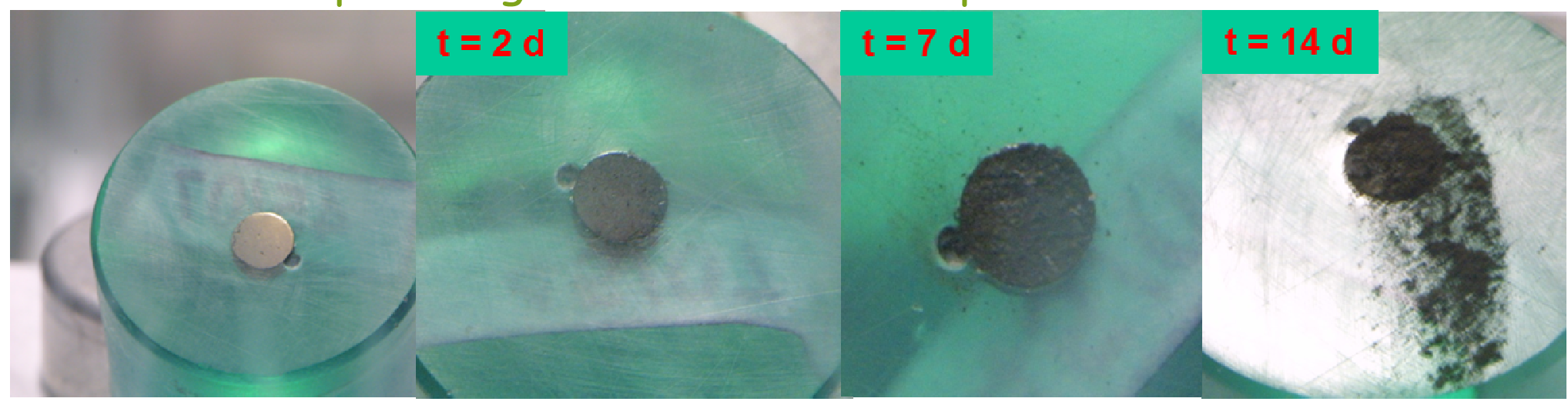

Fast oxidation kinetics of the surface samples...

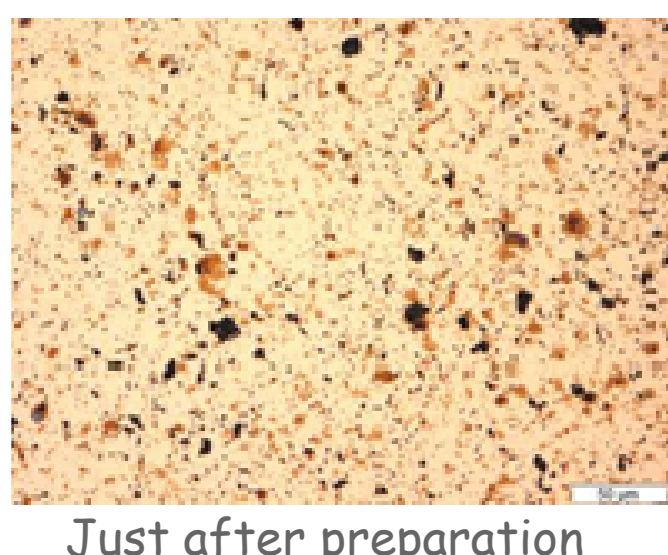

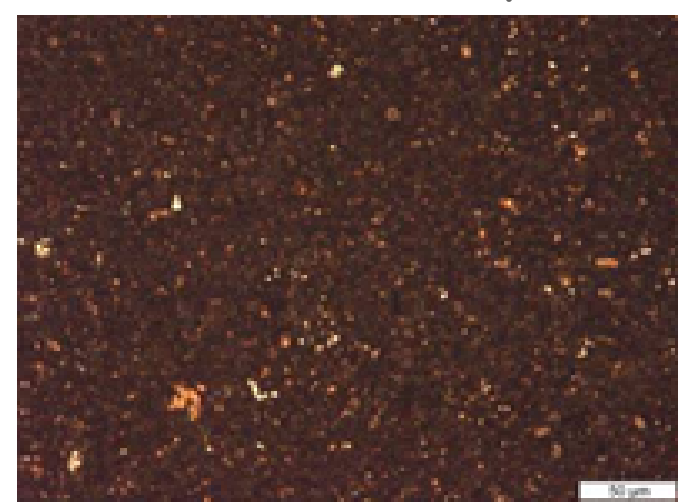

1 day after preparation

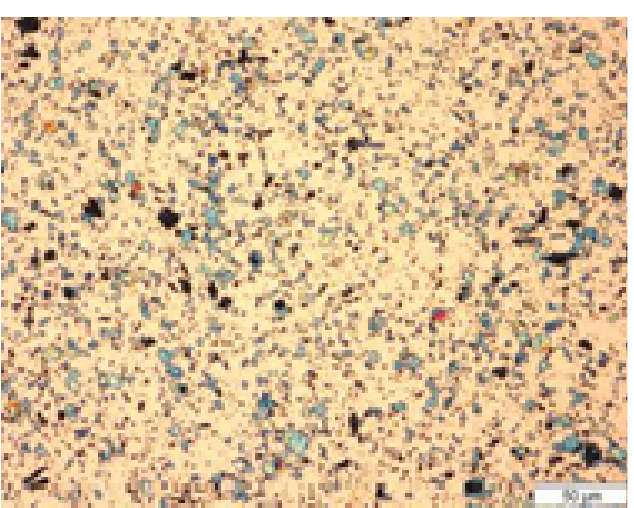

after $48 \mathrm{~h}$ under vacuum

which can be limited by a specific preparation. 


\section{CEA ALTERNATIVE FABRICATION ROUTES}

\section{MIN口S}

\section{Use of new oxide precursors}

whose synthesis is based on the co-conversion of actinides

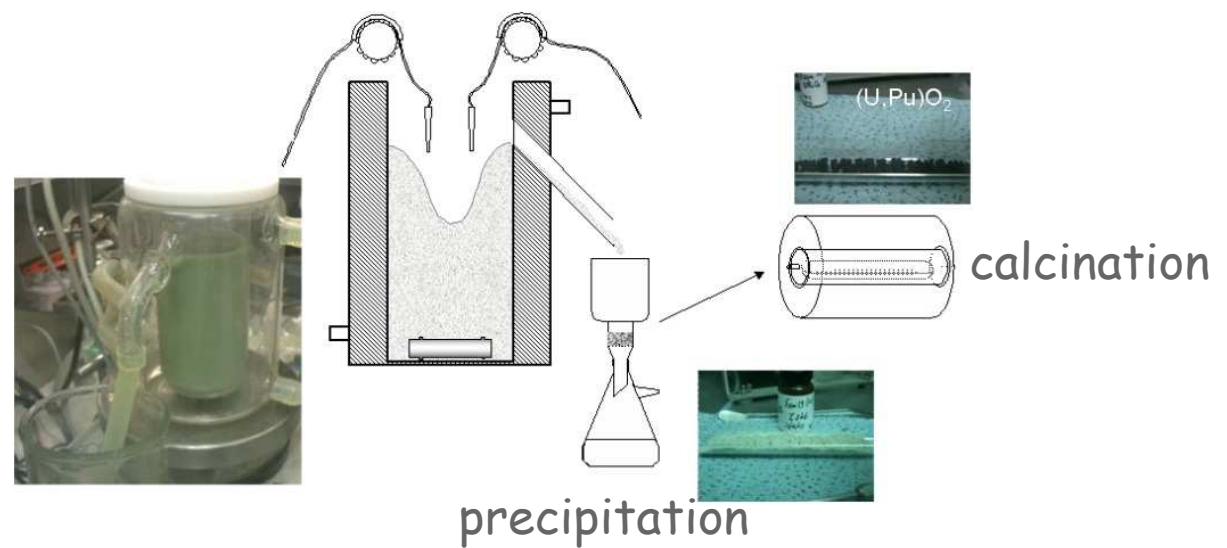

$\Leftrightarrow$ to simplify the manufacturing process by reducing the number of process steps (removal of the co-blending step)

$\Leftrightarrow$ to avoid the additional oxygen contamination of the final product

$\Leftrightarrow$ to limit the radiation exposure to the operators

potential starting materials, instead of $\mathrm{UO}_{2}$ and $\mathrm{PuO}_{2}$ :

$\checkmark(\mathrm{U}, \mathrm{Pu}) \mathrm{O}_{2}$

$\checkmark$ precursors obtained by direct incorporation of carbon graphite or a carbon molecule in the structure of the mixed oxalate 


\section{CO-CONVERTED OXIDES USED AS PRECURSORS}

\section{MIN口S}

Carboreduction at $1520^{\circ} \mathrm{C}$ for:

$\checkmark$ co-grinded $(C O B)$ and co-converted oxides (COP)

$\checkmark$ two plutonium contents: $11 \%$ and $\sim 45 \%$

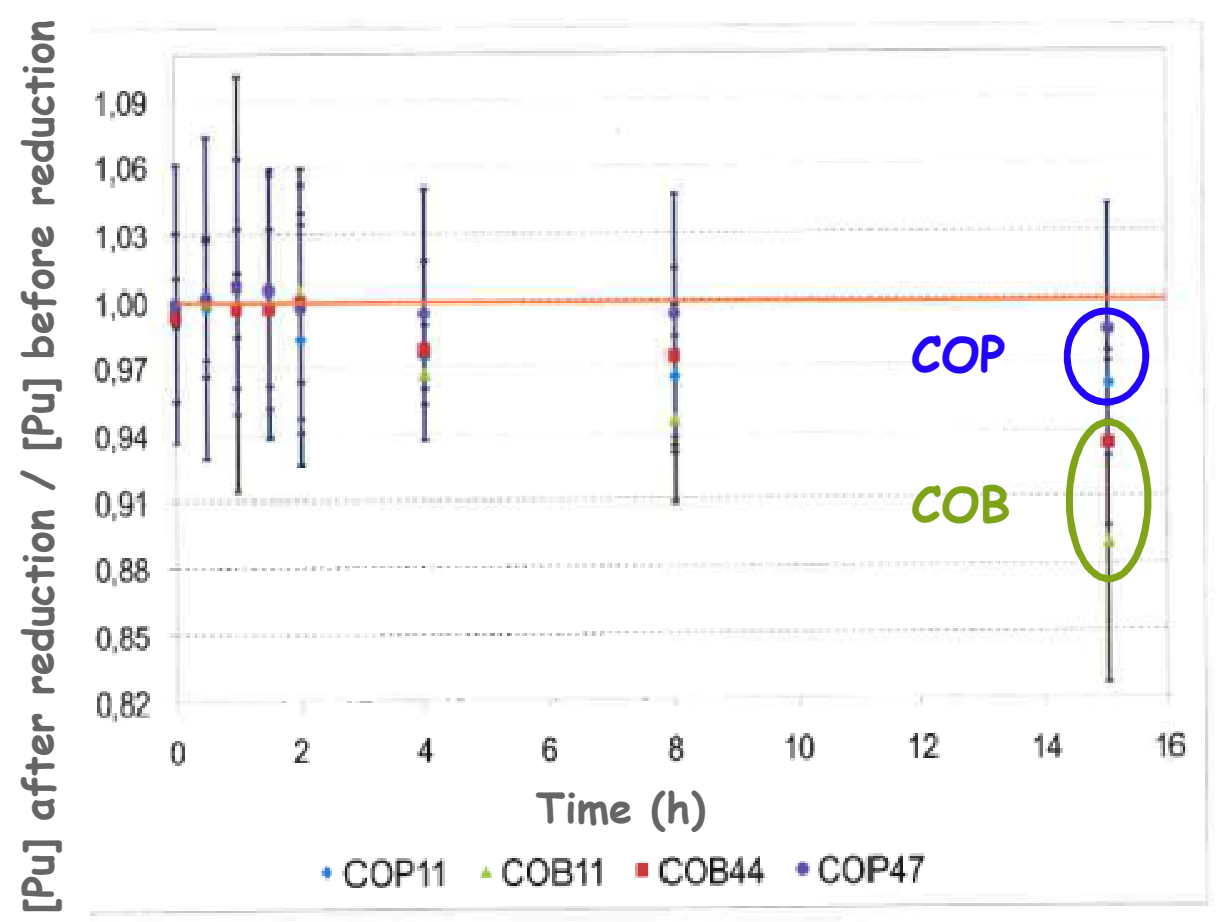

A. Handshuh, Thèse de Doctorat de I'Université des Sciences et Technologies de Lille, Octobre 2010

Synthèse des carbures d'U-Pu: Influence des précurseurs et mécanismes réactionnels de la carbothermie des systèmes lanthanides et actinides

$\Leftrightarrow$ A lower plutonium volatilization when $(U, \mathrm{Pu}) \mathrm{O}_{2}$ is used as starting powder, rather than co-grinded $\mathrm{UO}_{2}$ and $\mathrm{PuO}_{2}$ 
1 - An advanced fuel

2-Fabrication process and controls

3-Experimental results

4-Conclusions and prospects

MANUFACTURED MIXED CARBIDES 


\section{CEA CARBIDE COMPOSITION}

\section{MIN口S}

$\checkmark$ Various amounts of oxygen after carboreduction, especially after milling: oxygen pickup from 800 to more than 10000 ppm, reduced by sintering

$\checkmark$ Two phases identified by XRD, and in some cases (U,Pu) $\mathrm{O}_{2}$

Lattice parameters in agreement with those reported in the literature:

$$
\begin{aligned}
& 4,950 \AA \leq a \leq 4,970 \AA \text { for } \mathrm{fcc}(U, \mathrm{Pu}) C \\
& 8,092 \AA \leq a \leq 8,102 \AA \text { for } c c(U, P u)_{2} C_{3}
\end{aligned}
$$
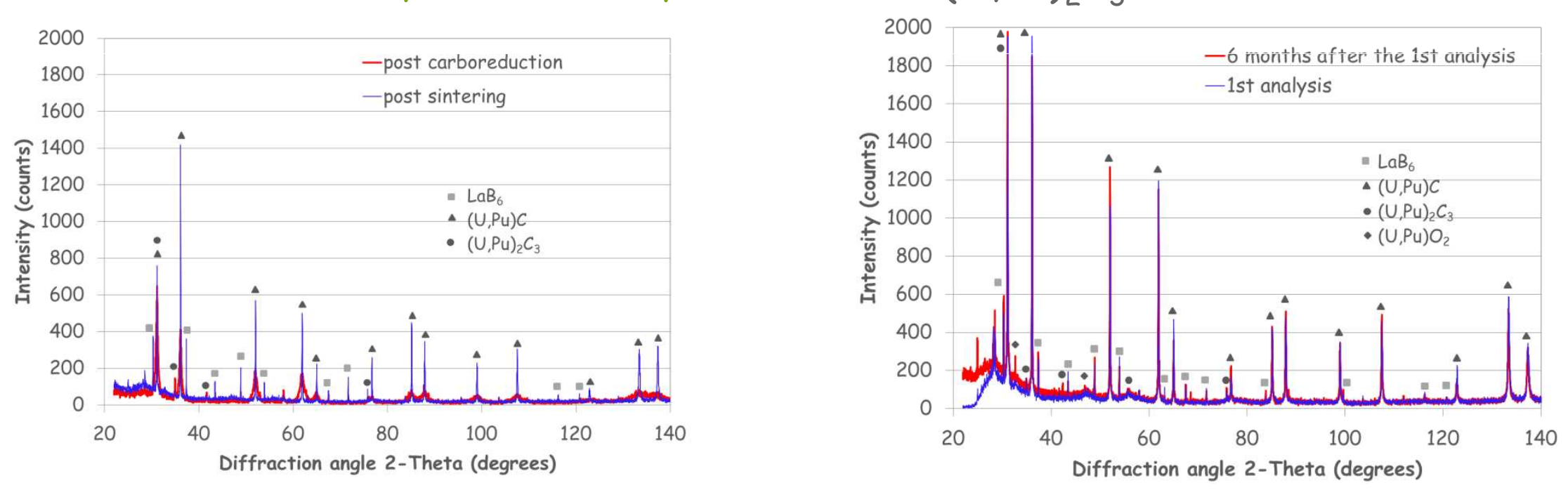

No significant differences between post carboreduction and post sintering patterns, and 6 months after the sample preparation 


\section{ACHIEVEMENT OF DIFFERENT DENSITIES: FROM GREEN TO SINTERED PELLETS}

\section{MIN口S}

\section{P 500 MPa}
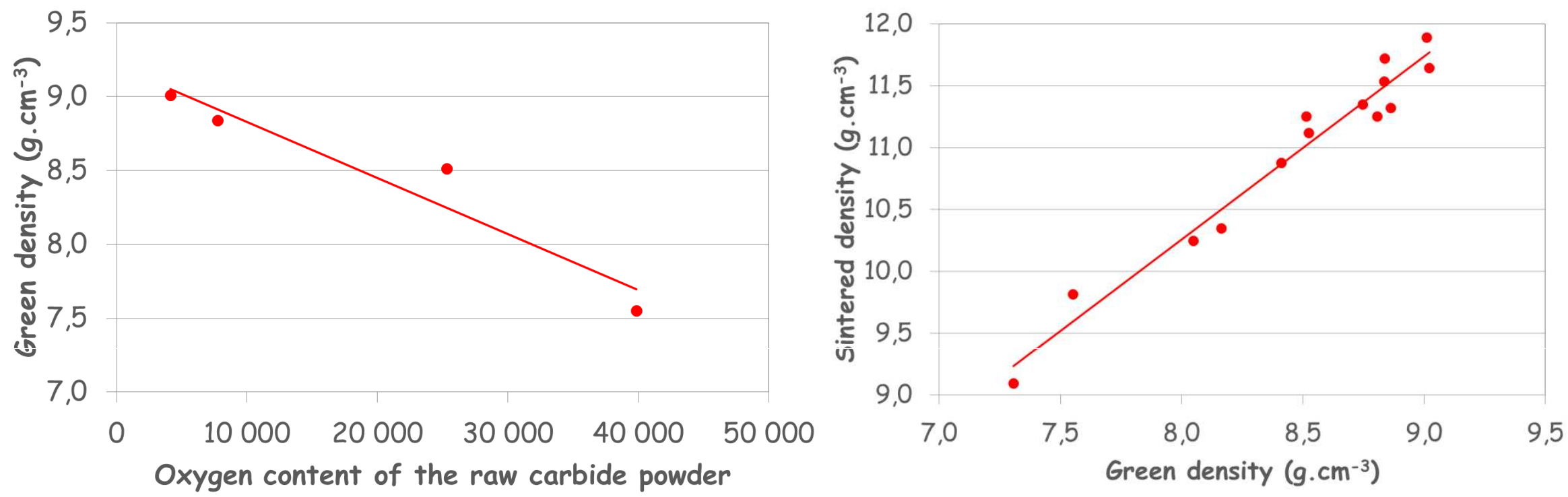

$$
\left(\mathrm{g} . \mathrm{cm}^{-3}\right)
$$

$\Rightarrow$ decrease of the green density as the oxygen content in the raw carbide powder increases

$\Rightarrow$ increase of the sintered density as the green density increases

$\Leftrightarrow$ Importance of the oxygen content in the raw carbide 


\section{ACHIEVEMENT OF DIFFERENT DENSITIES: EFFECT OF A PORE FORMER ADDITION}

\section{MIN口S}
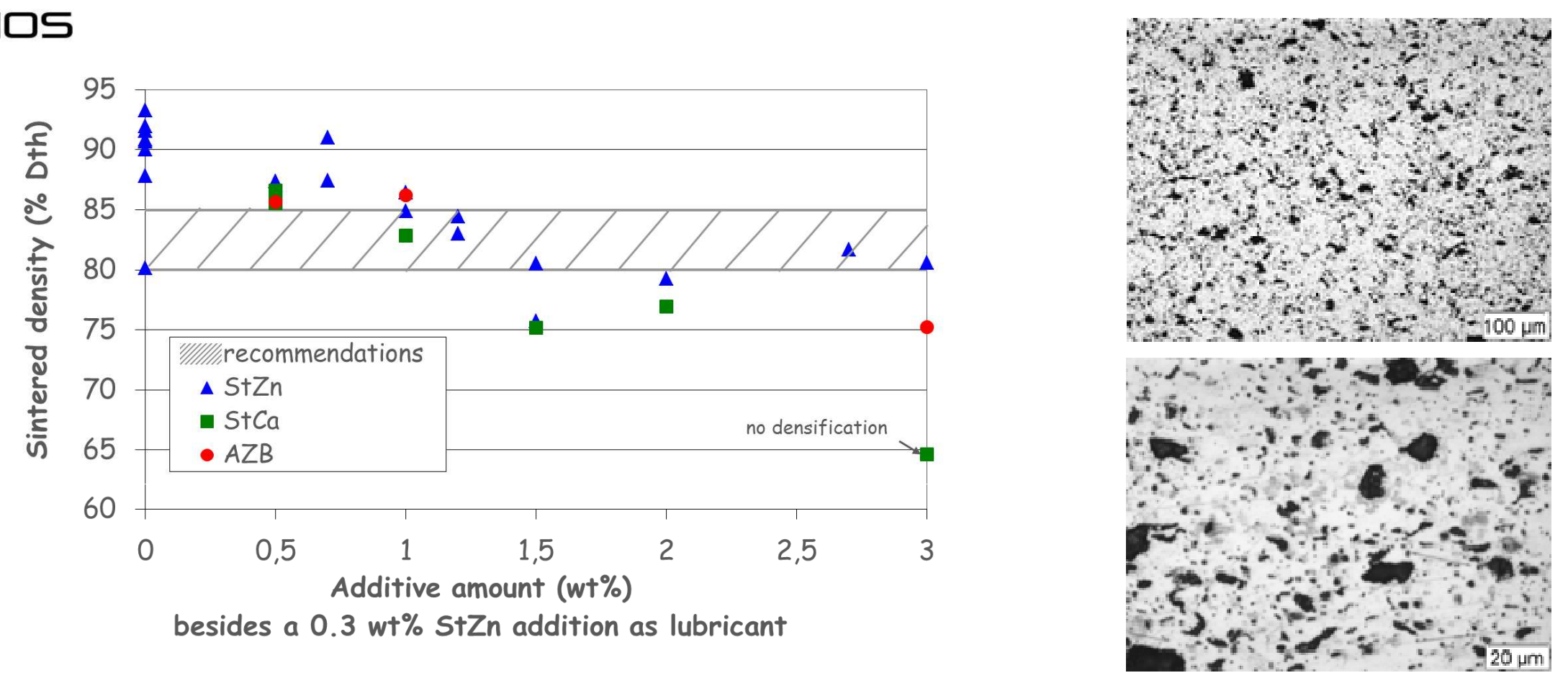

$84 \%$ Dth carbide using 1.2 wt\% StZn

$\Rightarrow$ Decrease of the sintered density with increasing additive amounts

$\Rightarrow$ A homogeneous distribution of the porosity and some macropores

$\Leftrightarrow$ an amount of 1 to 1.5 wt\% of pore former is suitable to reach the specified sintered density 


\section{ACHIEVEMENT OF DIFFERENT DENSITIES: ESTIMATION OF THE SINTERED DENSITY}

\section{MIN口S}

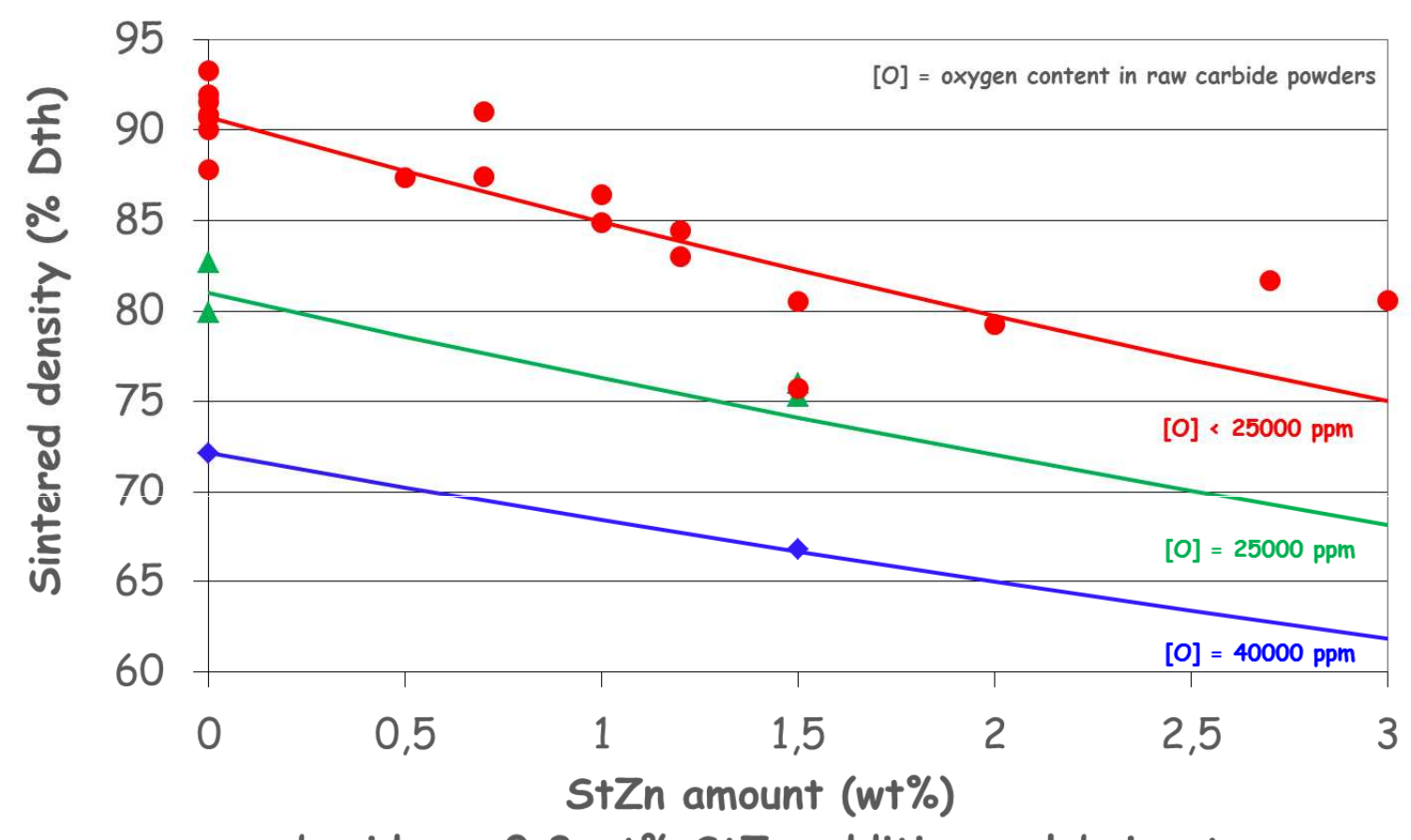

besides a $0.3 w+\% \mathrm{StZn}$ addition as lubricant

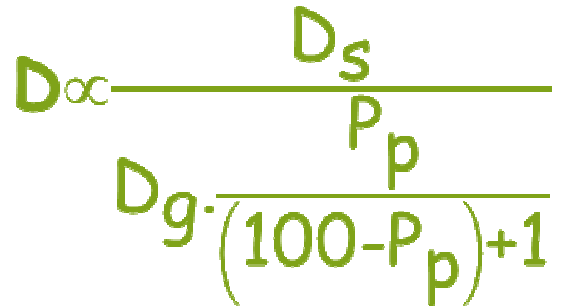

Ds : sintered density without pore former Dg : green density Pp: weight percentage of pore former

After

Y. Honda et al.

Ceram. Bull., 60 [12], 1296-1299 (1981) for $\mathrm{UO}_{2}$ pellets

$\Rightarrow$ Estimation of the sintered density as a function of the green pellet density, the sintered pellet density without additive and the pore former amount. 


\section{CEA ACHIEVEMENT OF DIFFERENT OPEN POROSITIES}

\section{MIN口S}
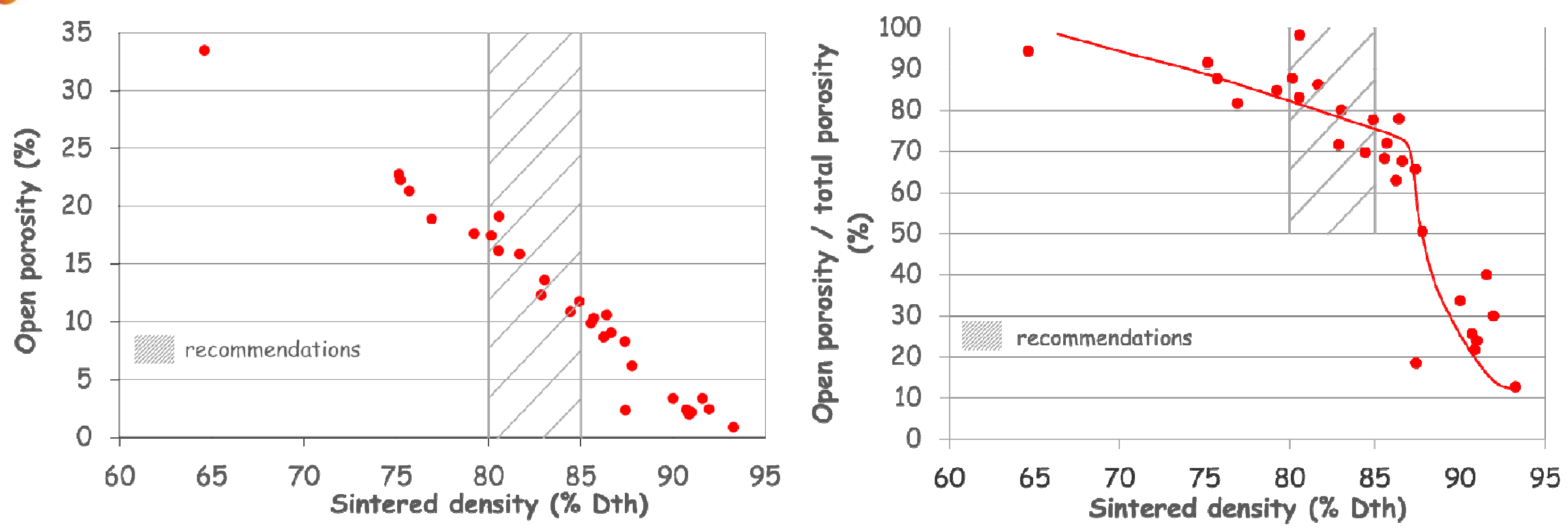

$\Rightarrow A$ decrease in the open porosity with increasing sintered density

$\Rightarrow$ A fraction of open porosity Po/Pt $\geq 70 \%$ for sintered densities lower than $85 \%$ of theoretical

$\Leftrightarrow$ in agreement with the recommendations (Po/Pt > 50\%) 


\section{CEA CARBIDE OXYGEN CONTENT}

\section{MINDS}

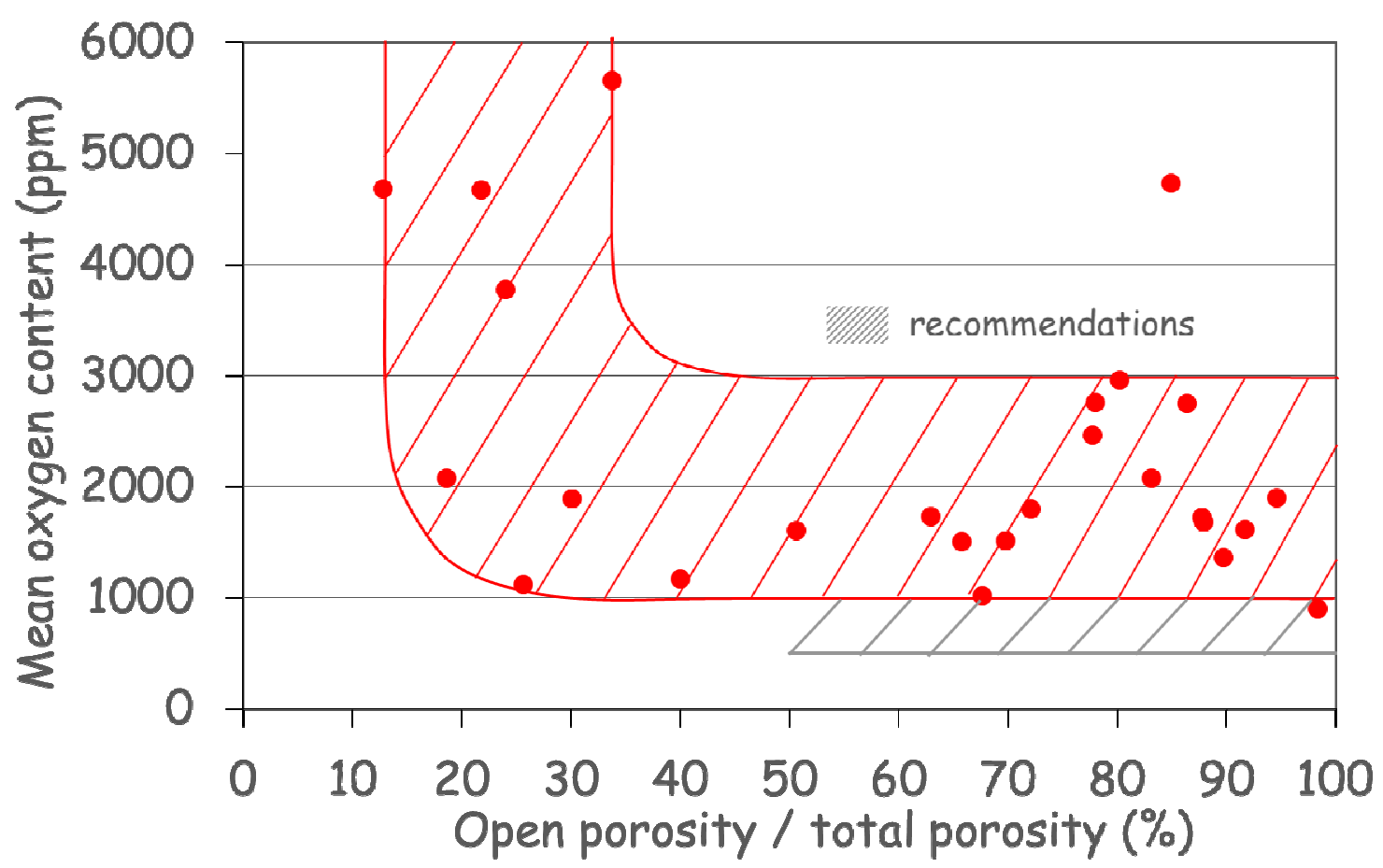

$\Rightarrow$ A wide range of oxygen content measured in sintered pellets

$\Rightarrow$ An oxygen content lower than 3000 ppm for a fraction of open porosity $\mathrm{Po} / \mathrm{Pt} \geq 40 \%$

$\Leftrightarrow$ a lower reachable oxygen content of $1000 \mathrm{ppm}$, the upper limit of the recommendations 
1 - An advanced fuel

2-Fabrication process and controls

3-Experimental results

4-Conclusions and prospects

CONCLUSIONS AND PROSPECTS 


\section{CEA CONCLUSIONS}

MINDS

> Hyperstoichiometric mixed uranium-plutonium carbides (mono(xy)carbide, and sesquicarbide as a secondary phase) can be produced by conventional carbothermic reduction and sintering $\Rightarrow$ suitable procedures

> Some Pu loss is unavoidable during carboreduction, but it can be limited.

$>$ Raw carbides can present various amounts of oxygen, which may affect the green density and hence the sintered density.

$>$ The use of organic pore formers allows:

$\checkmark$ an adjustment of the sintered density,

$\checkmark$ the fabrication of mixed carbides with an open-pore microstructure.

$>$ Sintered carbides with a high open porosity exhibit a lower oxygen content.

$\Leftrightarrow$ Achievement of a carbide fuel within the specified limits is possible, except for the oxygen content ([O]<1000 ppm):

D $80 \%$ DT, Po/Pt 70\%, [O] 2000 ppm when 1.5 wt\% StZn is added 


\section{EFFORTS MUST NOW FOCUS ON...}

MINDS

$>$ The robustness of the fabrication process : perhaps more complex phenomena at a larger scale?

$>$ The development of control methods (X-ray diffraction) and fine characterization techniques (Optical and Scanning Electron Microscopies, Electron Probe Micro-Analyzer) to guarantee the stability of carbides before and during the analysis.

$>$ The achievement of specified densities by adapting the sintering cycle (duration and / or temperature) instead of using pore formers.

> The carbide synthesis from innovative precursors in order to reduce the volatilization of plutonium.

> The mastery of the carbide reactivity with oxygen (kinetic and thermodynamic approaches of the U-Pu-C-O system), but also with moisture and nitrogen, in order to define optimal manufacturing conditions. 


\section{THANK YOU FOR YOUR ATTENTION}

WITH THANKS TO THE TEAM OF THE LABORATORY FOR THE STUDY \& EXPERIMENTAL FABRICATION OF ADVANCED FUELS 